\title{
Base Nacional Comum Curricular e currículo da Educação Física: qual o lugar da Diversidade cultural?
}

\author{
Marcio Antonio Raiol dos Santos* \\ Pedro Paulo Souza Brandão**
}

\begin{abstract}
Resumo
Este artigo tem o objetivo de discutir a BNCC e como esta apresenta a perspectiva da Diversidade cultural a partir do currículo cultural da Educação Física. A partir da análise concluímos que: A BNCC trata a Diversidade cultural com superficialidade e torna-se contraditória ao se estruturar por habilidades e competências; em relação ao Currículo da Educação física, expressa o potencial de apenas alguns conteúdos nessa temática, quando é necessário que todos os conhecimentos sejam contextualizados para que os sujeitos de todos os grupos sejam contemplados com um currículo em uma perspectiva cultural.
\end{abstract}

Palavras-chave: Diversidade Cultural; Currículo; Educação Física.

\section{National Curricular Common Base and Physical Education curriculum under the perspective of the Cultural diversity}

\begin{abstract}
This article aims to discuss the curriculum of Physical Education in the perspective of cultural diversity, focusing on primary education based on an analysis of the National Curricular Common Base. The Cultural Curriculum of Physical Education is the theoretical matrix chosen to carry out this discussion. From the analysis we conclude that: The BNCC treats Cultural diversity with superficiality and becomes contradictory when structuring by skills and competences; the document articulates with neoliberal logic and remains in eclecticism; In relation to content, it expresses the potential of only some content in this theme.

Keywords: Cultural diversity; Curriculum; Physical Education.

\section{Introdução}

Diversidade Cultural: conceitos, raízes históricas e implicações no Currículo
\end{abstract}

Este estudo tem o objetivo de discutir a Base Nacional Comum Curricular, aprovada pelo Conselho Nacional de Educação, e como esta apresenta a perspectiva da diversidade cultural a partir do currículo da Educação Física, tendo como referência teórica o Currículo cultural da Educação Física proposto por Neira (2011a). Para isso, dividimos este artigo em três seções: na primeira, apresentaremos a Diversidade cultural enquanto fenômeno e suas implicações no currículo escolar, principalmente no que tange ao currículo da Educação física no Ensino Fundamental. Na segunda seção, analisamos como os documentos oficiais das políticas educacionais para o Ensino Fundamental precursores da BNCC trataram e vêm tratando a Diversidade cultural e quais os possíveis impactos no currículo da Educação Física escolar. $\mathrm{Na}$ terceira seção, discutimos a BNCC pela perspectiva da Diversidade cultural, investigando de que forma esse documento trata a temática e quais as aproximações e distanciamentos entre os mesmos.

\footnotetext{
* Endereço Eletrônico: marsraiol@ gmail.com

** Endereço Eletrônico: pedropaulo_151@hotmail.com
}

A Diversidade Cultural, de acordo com Kiyindou (2005), pode ser entendida como a multiplicidade de culturas, subculturas e populações que compartilham de valores e ideais comuns em cada grupo. $\mathrm{O}$ mesmo autor alega que esse termo também viria a ser usado para definir a coexistência de diferentes culturas em um mesmo espaço.

Para Hanashiro e Carvalho (2005), a

Diversidade cultural é definida como a representação de pessoas pertencentes a grupos claramente distintos do ponto de vista de suas culturas, vindo a ser a mistura de indivíduos diferentes culturalmente em uma sociedade na qual essas culturas são compartilhadas.

Gomes (2007, p. 17), por sua vez, acredita que a Diversidade cultural "pode ser entendida como a construção histórica, cultural e social das diferenças" que vão além das características genéticas visíveis descritas pelos fatores biológicos, mas são criadas pelas pessoas em um meio social também produzido por estas.

$$
\text { Fleury (2000) conceitua a Diversidade }
$$


cultural como uma mistura de pessoas interagindo socialmente com identidades diferentes, que formam grupos com várias características, sendo minoritários ou majoritários. Estes últimos possuem privilégios em relação aos demais devido às relações de poder estabelecidas historicamente.

Hall (2015) define três concepções de identidade: a do sujeito do Iluminismo; sociológico; e pós-moderno.

A concepção sociológica descrita por Hall (2015), em particular, versa sobre o diálogo entre esse sujeito e os outros a sua volta. A identidade, portanto, era formada não apenas pelo "eu", mas pela sua interação com a sociedade, na qual os outros mediavam as relações do sujeito com os valores e os símbolos presentes no meio social.

Sendo assim, essa se relaciona com os pressupostos da Diversidade. Esse fenômeno dá-se concomitantemente com a construção dos processos identitários, que, de acordo com Gomes (2007), acontecem de forma interacional, em um diálogo entre as culturas, entre o indivíduo e o contexto social em que vivem.

Historicamente, a Diversidade cultural se constituiu como campo de estudo científico entre os séculos XIII e XIV para legitimar as hierarquias culturais que pregavam a superioridade de uma cultura sobre as outras (KADLUBLITISKI; JUNQUEIRA, 2009). Na contemporaneidade, a Diversidade cultural começou a ser explorada por estudos da área da administração e economia, como uma alternativa de "gerir" a Diversidade cada vez mais presente nas empresas (HANASHIRO; CARVALHO, 2005).

Como fenômeno, a Diversidade cultural aparece como resistência ao processo de globalização, definida por Hall (2015) como um complexo de forças de mudanças que ultrapassam fronteiras e conectam as pessoas, as instituições e as culturas, resultando em transformações no espaço e no tempo.

A globalização vem atada aos avanços tecnológicos e econômicos frutos de um projeto neoliberal. O Neoliberalismo, segundo Matos (2008), é uma corrente que surgiu pós-segunda guerra mundial, na Europa Ocidental e na América do Norte. No entanto, teve seu marco durante a crise do petróleo na década de 1970. Entre os principais teóricos estão Ludwig Von Mises, Friedrich Hayek e Milton Friedman.

A ideologia neoliberal tem como princípios: a pouca ou nenhuma intervenção do Estado na economia e no mercado de trabalho, sendo este apenas um facilitador com a flexibilização de leis e regras para a economia; a privatização de empresas estatais; a defesa da propriedade privada como fundamento da liberdade individual; a livre circulação do capital e o favorecimento da globalização (MATOS, 2008). Portanto, atende ao modo de produção capitalista.

O favorecimento da globalização faz com que esse processo rompa fronteiras nacionais e siga interesses de mercado que buscam a universalização de hábitos e costumes. De acordo com Silva e Brandim (2008), a globalização se configura como um processo contraditório, pois, ao mesmo tempo que tenta padronizar as culturas, tendo como referência a cultura euro-americana e branca, consoante ao paradigma hegemônico, faz emergir e conecta as culturas, favorecendo os intercâmbios culturais tanto pelas trocas de informações facilitadas pelas tecnologias de comunicação, quanto pela facilitação da circulação de pessoas.

Dados os riscos de opressão às culturas dos diversos grupos no mundo, Hall (2015) destaca que os movimentos de resistência à globalização vêm reforçando identidades locais e despedaçando as identidades nacionais, que foram construídas, em grande parte, com opressão. Ainda segundo o autor, novas identidades vão sendo formadas pelos intercâmbios culturais.

Esse processo aumentou as discussões sobre a Diversidade cultural e o reconhecimento das diferenças. Essas discussões começam a ser travadas com mais frequência durante a década de 1990 e, para evitar maiores problemas advindos das opressões que a globalização fazia sobre a Diversidade, o sistema capitalista resolveu atender às reivindicações dos movimentos de resistência (SILVA; BRANDIM, 2008).

Com isso, os países criaram políticas públicas com o intuito de mediar o diálogo com a Diversidade na esfera mundial. Em 2001, a Declaração Universal sobre a Diversidade Cultural foi uma tentativa de promoção da Diversidade, resultando, em 2005, na convenção sobre promoção e proteção da Diversidade cultural, realizada pela Organização das Nações Unidas para a Educação, Ciência e Cultura - UNESCO (SILVA; BRANDIM, 2008).

Além desses eventos, os países, durante a década de 1990 e os anos 2000, passaram a adotar políticas públicas de promoção da Diversidade em diversas áreas, principalmente da Educação. A discussão que inicialmente tratava do acesso dos membros dos diversos grupos à Educação escolar 
teve a necessidade de avançar para a discussão do currículo, pois algumas arestas ainda precisavam ser aparadas, no que tange ao direito de grupos diversos à Educação escolar (SILVA; BRANDIM, 2008).

A principal dificuldade girava em torno da democratização do ensino que apenas deu acesso coletivo a uma Educação escolar. A partir de então, a grande massa adentra a escola com toda a sua Diversidade, mas o currículo permanecia voltada para a classe dominante, pois os saberes dessa classe são mais valorizados que os das demais. Do ponto de vista da cultura, elegeu-se uma cultura hegemônica, mais valorizada, o que continuou mantendo a escola como um espaço desigual (NEIRA, 2011a).

Para atender a essas carências, diversos documentos oficiais vem sendo publicados no Brasil desde a década de 1990, como a Lei de Diretrizes e Bases da Educação Nacional (LDB:9394/96); os Parâmetros Curriculares Nacionais (PCN's); a Conferência Nacional da Educação Básica; as Referências para a Formação de Professores Indígenas; as Diretrizes Curriculares Nacionais para a Educação das Relações Étnico-Raciais e para o Ensino de História e Cultura Afro-Brasileira e Africana e Orientações e as Ações para a Educação das Relações Étnico-Raciais. Todos esses documentos foram promulgados durante a vigência do Governo Lula, que compreende o período entre os anos de 2003 e 2010 (KADLUBITSKI; JUNQUEIRA, 2009).

Quanto ao currículo, esse é um campo com linhas de pensamento construídas historicamente, que podem ser didaticamente divididas de uma forma geral em teorias tradicionais, críticas e póscríticas.

As tradicionais, cujo surgimento ocorreu no início do século XX, preconizam os currículos escolares de forma prescritiva e linear com o intuito de atender aos interesses do modo de produção capitalista. Esses modelos só passaram a ser duramente contestados na década de 1960 em vários locais ao mesmo tempo (movimento reconceptualista, nos Estados Unidos e "Nova Sociologia da Educação", na Inglaterra, por exemplo) (SILVA, 2010).

As teorias críticas surgem como questionamento às ideias tradicionais, pois o currículo não pode ser neutro, uma vez que o conhecimento que é ensinado visa aos interesses da classe burguesa (SILVA, 2010). Louis Althusser é um dos autores que criticam a forma como o currículo era tratado. Para Althusser, as teorias tradicionais tinham o conhecimento como forma de aceitação do modo de produção capitalista e das condições privilegiadas da classe burguesa. Por meio do currículo, a escola, portanto, se tornava um dos aparelhos de controle ideológico do Estado, que, por meio do convencimento ou da força, mantém suas instituições como repressoras (SILVA, 2010).

A partir de então, o currículo passava a ter um posicionamento e começava a questionar a alienação das massas na sociedade burguesa sob a ótica marxista. Segundo Lopes e Macedo (2011), Passeron e Bourdieu também compõem a gama de autores de abordagem crítica, visto que definem os processos culturais como sendo importantes na manutenção das relações de classe, pois a cultura das classes dominantes, conforme explica Silva (2010), são as que teriam valor social e, assim, se transformam em capital cultural que se manifesta de várias formas, desde os gostos e hábitos até as formas institucionalizadas: títulos, diplomas e certificados.

Portanto, as relações de poder se estabelecem a partir das lutas de classe e há um compromisso da perspectiva crítica com a classe trabalhadora. Essas ideias, mais tarde, chegam ao Brasil e influenciam as diversas áreas do conhecimento (SILVA, 2010).

No caso da Educação Física como disciplina, esta chega ao Brasil na transição do século XIX para o século XX, com fortes ligações com as teorias tradicionais do currículo, permanecendo com essas características por várias fases de sua história (SOARES, 1994).

Em seu primeiro momento, essa disciplina teve o objetivo de construir um novo homem capaz de suportar as demandas do modo de produção capitalista. O que ficou conhecido como Educação Física higienista no século XIX preconizava o nacionalismo e o patriotismo, dava ênfase à promoção da saúde e visava à formação de indivíduos fortes e livres dos maus hábitos, considerados obstáculos para o desenvolvimento da sociedade. Esses princípios nortearam o Brasil em uma república recém-criada, que buscava a modernização do país com o intuito de deixar para trás o atraso (SOARES, 1994).

Betti (1991) afirma que, em meados dos anos 30, a Educação Física ganhava uma nova característica que ficou conhecida como Militarista, que consistia no desenvolvimento do corpo e da personalidade por meio do método utilizado pelos militares franceses. $\mathrm{O}$ autor destaca que as políticas 
educacionais da época davam ênfase aos valores nacionalistas, mas se diferenciavam da perspectiva higienista pelas suas tendências eugênicas, que visavam à purificação da raça por meio do aperfeiçoamento físico e da formação das qualidades morais.

A partir da subida dos militares ao poder em 1964, o Estado vive um clima de guerra e uma perspectiva ideológica de segurança nacional. Surge, portanto, desse contexto a necessidade de criar instrumentos de controle ideológico, de fortalecer a população e desenvolver o patriotismo para uma possível guerra contra as ameaças ao regime (BETTI, 1991).

Dessa forma, a Educação Física teve um papel fundamental para a ditadura militar, pois possuía características de disciplina, ordem e respeito e adequava-se perfeitamente ao modelo ideológico o Estado. O incentivo a essa disciplina, portanto, ganhava força na legislação educacional, pois ela era enxergada como um dos instrumentos para a formação do homem integral, que, seguindo a concepção da época, se tratava do indivíduo apto para a guerra (BETTI, 1991).

Com as medidas adotadas, o Esporte passa a ser o conteúdo hegemônico da Educação Física, mais precisamente o Esporte de alto rendimento, voltado para a formação de atletas nas escolas, o que promoveu a exclusão de muitos alunos, pois nem todos tinham aptidão para o Esporte competitivo. Assim, o incentivo ao Esporte de alto rendimento no currículo da Educação Física escolar colaborava para a formação de indivíduos aptos a servir o país em uma possível guerra, além de inculcar os princípios competitivistas do modelo capitalista e promover a disciplina, a ordem e o respeito pelo regime, auxiliando, portanto, na contenção de revoltas, uma adequação ao modelo econômico (BETTI, 1991).

A alienação promovida pelo Estado brasileiro se refletiu no esvaziamento crítico da Educação Física nas escolas, pois o método esportivo presente no currículo assentava-se no ensino tecnicista e mecanicista, sem qualquer reflexão sobre sua prática, focando seus objetivos educacionais na perfeição dos gestos técnicos dos movimentos com repetições exaustivas (BETTI, 1991).

Na década de 1980, há um movimento renovador na Educação Física. Na perspectiva do currículo crítico, esse movimento buscou desatar essa disciplina do seu caráter acrítico, construído historicamente, e culminou com a formulação de abordagens pedagógicas, com destaque para a crítico-superadora e a crítico emancipatória (KUNZ, 1994). A primeira consiste em uma abordagem específica da Educação Física, a qual valoriza a formação de indivíduos que rompam com a ideologia dominante e possam intervir criticamente na sociedade, sobretudo no viés político. A abordagem crítico-superadora, portanto, centra suas ideias na luta de classes, questiona as ideias dominantes e abre espaço para a reflexão sobre os conteúdos a serem abordados no currículo da Educação Física, justamente com o objetivo de romper com a lógica capitalista (COLETIVO DE AUTORES, 1992).

A segunda, por seu turno, se caracteriza pela formação crítica dos sujeitos por meio do desenvolvimento da autonomia, da compreensão da realidade social em que os sujeitos vivem e por meio da reflexão. Essas competências podem conduzir os indivíduos a intervirem e a transformarem a sociedade, especialmente quanto ao desenvolvimento da autonomia (HENKLEIM; SILVA, 2007).

No sentido de ampliar o debate da luta de classes, as teorias pós-críticas, segundo Pinheiro (2009), surgem como complemento e aprofundamento da visão crítica. Essas teorias caracterizam-se por dar voz a sujeitos ocultos no âmbito das teorias tradicionais e não tão abordados nas teorias críticas. Essa perspectiva afirma que, assim como existem disparidades relacionadas às classes, essas disparidades também estão presentes na cultura, etnia, gênero, raça e sexualidade (SILVA, 2010).

De acordo com Silva (2010), no âmbito das teorias pós-críticas, diversas correntes problematizam as relações de poder nos campos específicos. A pedagogia feminista, por exemplo, aborda o campo do gênero, promove a contestação da sociedade patriarcal e toma como base o privilégio de recursos materiais e simbólicos da sociedade. O currículo étnico-racial faz suas críticas à estrutura quanto às desigualdades relacionados à raça, sendo os grupos étnicos objetos da discussão do favorecimento de uma determinada raça sobre as etnias consideradas minoritárias, mas que igualmente fazem parte do contexto escolar e social. O currículo multicultural estuda questões culturais presentes na escola sob os princípios de inclusão e emancipação, possibilitando superar os reducionismos e as contradições.

Reforçando essa ideia, Ribeiro (2016) defende uma concepção curricular em diálogo entre 
os olhares críticos e pós-críticos. Como defendem os autores, devemos, portanto, abordar as aproximações entre essas ideias.

Tais aproximações consistem, primeiramente, na contestação das teorias tradicionais do Currículo, pois Ribeiro (2016) destaca que teóricos como Henri Giroux e Peter McLaren absorvem ideias de ambas as teorias, tornando-as híbridas, e conseguem compreender as relações de poder na discussão das diferenças, no que tange às teorias pós-críticas, mas sem esquecerem-se da totalidade, da sociedade de classes do capitalismo, conforme discutem as teorias críticas. Henri Giroux alega ainda que as teorias pós-críticas são teorias críticas com enfoques diferentes. Essas influências tornam difíceis o estabelecimento dos limites de onde terminam as perspectivas de uma teoria e onde iniciam as da outra (RIBEIRO, 2016).

Sendo assim, por trabalharmos com a perspectiva da Diversidade cultural, optamos por assentar este artigo em um posicionamento póscrítico ao discorrer sobre uma temática mais específica quanto ao debate dessas perspectivas. Deixamos claro, no entanto, que não pretendemos desprezar as teorias críticas, mas aprofundar a discussão para compreender os desafios para transformação do currículo escolar de modo a atender à diversidade cultural presente na escola (NUNES; RUBIO, 2008).

O pensamento pós-crítico busca dar voz aos grupos que antes eram silenciados pelo currículo hegemônico e, por essa razão, apresenta como proposta um currículo que possa considerar as culturas dos diversos grupos presentes na escola e valorizar as diferenças.

Por conta disso, tomaremos como base o Currículo cultural da Educação Física. Esta concepção foi formulada por Neira (2011b) e tem como pressupostos:

1- Reconhecer a Diversidade e promover o diálogo entre as culturas;

2- Levar em consideração a cultura dos alunos e confrontá-la com a cultura escolar, pois os alunos também precisam ter acesso à cultura dominante;

3- Considerar as práticas corporais como artefatos de identidade dos sujeitos, que possibilitam o aproveitamento dos conhecimentos trazidos pelos sujeitos para a escola com o objetivo de obter transformações sociais;
4- Contextualizar as práticas corporais para que os alunos pertencentes aos grupos minoritários sejam contemplados com conhecimentos que estejam relacionados à sua realidade (NEIRA, 2011a);

5- Igualar a cultura popular com a cultura escolar por meio de um entrecruzamento desses saberes, estabelecendo um diálogo entre eles e, assim, proporcionar uma formação humana de resistência à padronização promovida pelo currículo colonizado pelos ideais hegemônicos, no qual existe uma única cultura valorizada (NEIRA; NUNES, 2011).

De acordo com esses pressupostos, Lima e Neira (2010) afirmam que as práticas corporais hibridizam a maneira em que ocorre o entrecruzamento das Culturas no diálogo dos diversos grupos. Todas as manifestações da cultura corporal, portanto, deverão ser tematizadas na escola, tanto as hegemônicas quanto as historicamente marginalizadas, atribuindo o mesmo valor a todas elas.

O currículo cultural da Educação Física se aproxima dos conceitos pós-críticos e rompe, portanto, com a lógica homogeneizadora do currículo. Os ideais dominantes tomam conta do currículo escolar com o objetivo de difundir uma cultura universal a partir de seus preceitos, deixando de lado ou dando menos importância aos grupos minoritários presentes no âmbito escolar (NEIRA, 2011a).

A partir da cultura dominante, a Diversidade cultural, representada pelos grupos oprimidos, aparece na escola como o "diferente" e o "estranho" e seus integrantes devem, nesse espaço escolar, se apropriar da "verdadeira cultura" - a cultura branca e eurocêntrica - para saírem da ignorância (NEIRA, 2011a).

Como forma de resistência, o currículo, em uma perspectiva crítica, contesta o modo de produção capitalista com suas concepções que vão além de uma série de normas técnicas a serem seguidas (SILVA, 2010).

O currículo pós-crítico enxerga os desafios e as relações de poder com base na luta de classes, valorizando-a, ampliando a discussão das identidades e aproximando as diferenças a partir de uma relação que não apenas ultrapassa a convivência tolerante, como também estabelece uma constante troca de experiências para contestar os princípios dominantes (SILVA, 2010). 
É sob o prisma do currículo cultural da Educação Física que dialogaremos com a BNCC, no que se refere ao currículo do Ensino Fundamental na sua versão final aprovada em dezembro de 2017. Passaremos pelos documentos anteriores à Base para analisar a construção do currículo comum que vai orientar estados e municípios, além de examinar como este dialoga com a Diversidade cultural e quais serão as principais lacunas deixadas levando em consideração o momento político atual.

\section{A LDB e os Parâmetros Curriculares Nacionais: precursores de uma base comum e da Educação Física como componente curricular oficial}

De acordo com Rodrigues (2006), as políticas educacionais, implementadas na década de 1990, sofreram influência direta das políticas neoliberais, pois havia a necessidade de formar um novo modelo de trabalhador para servir ao mercado, especialmente pelas pressões geradas por órgãos internacionais como o Banco Mundial e a UNESCO, instituições que claramente defendem um projeto neoliberal.

A eleição do presidente Fernando Collor de Melo ao poder, portanto, deu início ao projeto neoliberal (que prosseguiu no governo seguinte) e às reformas curriculares que pretendiam formar essa nova mão de obra para servir a esse modelo, no contexto do final do Governo Fernando Henrique Cardoso. Rodrigues (2006) alega em sua análise, realizada no último ano de mandato $\mathrm{FHC}$, que este foi o que melhor pôs em prática a cartilha ditada pelos organismos burgueses internacionais.

É nesse contexto que a Lei de Diretrizes e Bases da Educação Nacional (LDB) (BRASIL, 1996) entra em vigor, durante o governo FHC. A carta magna do país, como já sinalizava a LDB, também fez menção à construção de uma base comum curricular que seria elaborada em colaboração com os estados e os municípios.

Apesar do avanço das políticas neoliberais, Kadlubitski e Junqueira (2009) afirmam que a LDB foi a primeira tentativa de satisfazer os anseios da valorização da Diversidade cultural no Brasil, mesmo que de forma tímida.

Essa tentativa reflete-se no artigo 26-A. Ele assegura que "Nos estabelecimentos de Ensino Fundamental e de Ensino Médio, públicos e privados, torna-se obrigatório o estudo da história e cultura afro-brasileira e indígena" (BRASIL, 1996) e concede um destaque à importância das diversas culturas para a formação da sociedade brasileira.
Ainda no texto da lei, o termo "Diversidade cultural" aparece de forma mais explícita no artigo 33, o qual se refere ao respeito à Diversidade cultural e religiosa no país.

Cabe ressaltar que a série de marcos legais que estabelecem reformas curriculares no Brasil possui um caráter impositivo, mesmo que de forma sutil. Um modelo "centro-periferia" (RODRIGUES, 2016), por exemplo, é característico das reformas curriculares de um projeto neoliberal, pois não institui qualquer espécie de diálogo com a sociedade. No caso da Educação, não há diálogo ou consulta com especialistas que vivenciam o campo.

Um exemplo marcante dessa política é, de acordo com Rodrigues (2006), a organização dos PCN's, um documento que visava a orientar os sistemas na construção de seus currículos, embora não fossem obrigatórios, como o próprio vocábulo "parâmetro" nos remete.

Kadlubitski e Junqueira (2009) alertam que, apesar de o documento introdutório do primeiro e segundo ciclos explicitar a importância de adequar conteúdos, critérios de avaliação e objetivos à Diversidade cultural, o documento referente ao terceiro e quarto ciclos do Ensino Fundamental elenca a Diversidade como tema transversal e não como uma temática inserida em todas as áreas.

Além disso, Os PCN's apresentam algumas dificuldades estruturais pelo fato de serem construídos com base em reformas curriculares ocorridas na Espanha e na Inglaterra, uma cópia de modelos de outros países com contextos completamente distintos do nosso. O Estado brasileiro, inclusive, convocou o mesmo consultor que participou das reformas nesses países, o psicólogo espanhol César Coll (RODRIGUES, 2006).

Se lermos os dois principais capítulos de Coll (1996), podemos perceber que os PCN's não passavam de uma cópia fiel da obra do autor, que teve sua primeira versão publicada no ano de 1987 , incluindo os quadros e esquemas presentes no livro. Portanto, ambos apresentam ecletismo tanto em seus aspectos gerais quanto nos específicos de cada campo do conhecimento (RODRIGUES, 2006).

Adentrando a Educação Física, percebemos a utilização de dois termos distintos para definir o objeto de estudo da disciplina: 1) Cultural Corporal: definida em uma seção específica do documento direcionado ao primeiro e segundo ciclos do Ensino Fundamental intitulada "Educação Física como Cultura Corporal" (BRASIL, 1997, p.23), determinada pelo Coletivo de Autores (1992, p. 26) 
como "conhecimentos socialmente produzidos e historicamente acumulados pela humanidade"; 2) Cultura Corporal de Movimento: estabelecida no documento para o terceiro e quarto ciclos em uma seção intitulada "Educação Física e a Cultura Corporal de Movimento" (BRASIL, 1998, p.27), que é diferenciada por Bracht (1999) por conferir ao movimento a especificidade da Educação Física.

No mais, a estrutura dos PCN's na área de Educação Física revela como princípios norteadores a diversidade, a inclusão, a integração e o convívio social. Darido et al. (2001) destaca como avanço o princípio da inclusão na área da Educação Física presente no documento. Em contraponto, Rodrigues (2006) revela que, embora a inclusão abranja também o engajamento dos educandos nos mais variados grupos sociais e não apenas na escola, esse conceito é tomado a partir de um ponto de vista superficial.

As discussões à época da elaboração dos PCN's fazem parte de uma discussão que era considerada superada e consolidou os Parâmetros como um documento que não levou a nenhuma definição de currículos dos sistemas e das instituições escolares. Entretanto, com o advento da BNCC, algumas delas voltam à tona (NEIRA; SOUZA JUNIOR, 2016). A partir disso, no caso da temática da Diversidade cultural, surge o seguinte questionamento: Qual é o trato e quais são os avanços da BNCC em relação à Diversidade cultural no currículo escolar, principalmente no campo da Educação Física?

A seguir, apresentaremos a estrutura da BNCC e destacaremos quais as interfaces desse documento com a Diversidade cultural no currículo da Educação Física no Ensino Fundamental.

\section{Base Nacional Comum Curricular (BNCC): aproximações e distanciamentos com o currículo cultural da Educação Física}

A BNCC é um documento normativo do Ministério da Educação (MEC) com o objetivo de nortear as propostas curriculares dos sistemas estaduais, municipais e instituições de ensino de todo o Brasil e possui um caráter de articulação, tanto com o Plano Nacional de Educação (PNE) e Conferência Nacional de Educação (CONAE), quanto com outras políticas, como a formação de professores e as ações para melhoria da infraestrutura das escolas (BRASIL, 2017).

Além disso, passou por um processo de consulta pública disponível no site do MEC, por meio do qual recebeu contribuições de todas as partes do país, o que não ocorreu na elaboração dos PCN's. Tal processo, portanto, pode ser considerado um avanço.

O documento teve duas versões antes da publicação de sua versão final no ano de 2017. Sua segunda versão já sofreu inúmeras críticas por parte de teóricos que a analisaram. As formulações presentes na BNCC causaram um grande debate, não apenas no aspecto geral da Educação, mas também nos campos específicos do conhecimento. $\mathrm{Na}$ Educação Física, por exemplo, diversos intelectuais se posicionaram diante do texto.

Moreira et al. (2016) alegou que o documento apenas é um mecanismo melhorado para atender às demandas neoliberais. A BNCC surgiu para atender às pressões dos órgãos internacionais, como o FMI e a UNESCO. A exemplo dos PCN's, tem como finalidade adequar as políticas educacionais para melhor servir ao capital. A autora ressalta que uma das grandes complicações para que esse documento atenda aos interesses neoliberais e não à classe trabalhadora é o fato de não apresentar uma concepção de sociedade e de homem, muito menos de Educação, que orientaria a formação que um currículo comum proporcionaria, sendo essa proposta permeada pelo ecletismo.

No entanto, Boscatto et al. (2016) defende que é necessário um currículo comum para ser implementado com vistas a melhorar os índices do IDEB como uma das metas do Plano Nacional de Educação (PNE). A partir desse último argumento, Moreira et al. (2016) destaca que, ao favorecer os sistemas nacionais de avaliação, a BNCC se coloca em favor da simples obtenção de resultados e deixou o aprendizado secundarizado.

O IDEB (Índice de Desenvolvimento da Educação Básica) é um indicador de qualidade da Educação Básica brasileira criado em 2007 e baseado nos mecanismos de avaliação externa. Esse índice, de acordo com Chirinéa e Brandão (2015), é uma das políticas implementadas para satisfazer as recomendações do Banco Mundial, no que diz respeito à qualidade da Educação. No entanto, essa qualidade é pautada na lógica de mercado da ideologia neoliberal.

Um dos mecanismos que formam o IDEB são os testes padronizados como a Prova Brasil, que integra os grandes sistemas de avaliação. A padronização da avaliação também fez com que o currículo fosse padronizado para atender às normas dessas avaliações. A padronização do currículo leva ao privilégio de conhecimentos de caráter 
dominante, o que demonstra a intenção dos sistemas de avaliação em atender aos interesses dos organismos internacionais, pois o IDEB se coloca como indicador de resultados e não de qualidade, de tal modo que os resultados são a prioridade das políticas neoliberais (CHIRINÉA; BRANDÃO, 2015).

Além disso, segundo Chirinéa e Brandão (2015), essa lógica responsabiliza a escola e os professores pelos possíveis fracassos na obtenção das metas estabelecidas, sem levar em consideração outros fatores que contribuem para o insucesso nas avaliações, como o sucateamento das escolas, a desvalorização e a precarização do trabalho docente e o currículo que não atende aos interesses do público que adentra o espaço escolar.

A prioridade em relação à obtenção de resultados, que leva à padronização do currículo, foi percebida no estreitamento de alguns campos do conhecimento, como a própria Educação Física, em favor dos conhecimentos da Língua Portuguesa e da Matemática, que são as disciplinas presentes nos sistemas de avaliação.

A redução do papel, não apenas da Educação Física, mas de todo o currículo, de acordo com Moreira et al. (2016), reduz também a função social da escola e o trabalho do professor a um ofício de transmissão de saberes, ao invés de ensino dos conhecimentos, esvaziando a escola de conteúdo.

Sobre a função social da escola, Sacristán (2000) aponta que se trata de fornecer uma Educação que possibilite ao sujeito a leitura da realidade em que vive, dos significados e da compreensão do mundo, com o objetivo de intervir para a transformação dessa realidade por meio do pensamento crítico e reflexivo.

Esse papel é antagônico aos interesses do projeto neoliberal das classes dominantes, cujo o objetivo é preparar os indivíduos para o mercado de trabalho, a fim de formar um exército de reserva para a lógica capitalista. É esta a intenção de um currículo que atende aos princípios neoliberais (SACRISTÁN, 2000).

As principais convergências entre as críticas estavam relacionadas à falta de clareza em muitos aspectos do documento. Rodrigues (2016), por exemplo, questionou a falta de clareza nos critérios utilizados para a escolha de conteúdos que terão um maior espaço no currículo. Outro fator que chama a atenção é a superficialidade com a qual conceitos tão caros para o campo acadêmico são evidenciados na redação do documento a partir de uma apropriação negligente.

Uma dessas confusões causadas pela falta de clareza dos conceitos é quanto ao próprio objeto de estudo da Educação Física, ora chamado de Cultura Corporal, ora chamado de Cultura Corporal de Movimento, que apresentam perspectivas diferentes (NEIRA; SOUZA JUNIOR, 2016).

A falta de clareza persiste na articulação dos conteúdos com os temas especiais. Para Rodrigues (2016), ainda não estão nítidas as formas como essa articulação se dará. O mesmo também vale para a integração entre os componentes da área da Linguagem.

Quanto aos conteúdos, Neira e Souza Junior (2016) defendem como proposital a não discriminação deles, pois os docentes devem ser encarregados de pensá-los de acordo com a singularidade de cada local. Moreira et al. (2016) se contrapõe a essa perspectiva com o argumento de que os conteúdos ficam localizados de forma abstrata e reduzida, além de não haver progressão entre os mesmos.

Para Moreira et al. (2016), todas essas incongruências no documento têm uma única finalidade: tornar a $\mathrm{BNCC}$ um aparato que responsabilizará a escola, os professores e os alunos pelos seus fracassos, segundo a lógica neoliberal de resultados obtidos em testes dos sistemas nacionais de avaliação.

Em 2017, a versão final aprovada pelo Conselho Nacional de Educação sofreu transformações em relação às versões anteriores. Uma das principais mudanças foi a organização dos principais fundamentos presentes na proposta por competências gerais comuns a toda a Educação Básica e conectados a princípios éticos, políticos e estéticos.

Os princípios orientam a construção das competências específicas de área, transforma-se depois nos componentes curriculares e tornam essa estruturação com base nesses fundamentos o principal diferencial da BNCC em relação aos documentos normativos escritos anteriormente (BRASIL, 2017).

As etapas de escolarização possuem componentes curriculares contidos nas áreas do conhecimento. Estas, por sua vez, estão divididas de acordo com Brasil (2017) em:

1- Linguagens: Língua Portuguesa,
Educação Física, Arte e Língua
Inglesa;
2- Matemática; 
3- Ciências da Natureza: Ciências;

4- Ciências Humanas: História e Geografia;

Cada área do conhecimento possui aprendizagens essenciais, que são chamadas de habilidades. Já que é um currículo orientado por competências, os conteúdos são denominados de objetos de conhecimento organizados em unidades temáticas.

Como podemos perceber, a BNCC surge com uma proposta baseada em habilidades e competências, o que gera conflitos para a construção de um currículo que valorize a Diversidade cultural, pois, apesar de a Diversidade estar citada nas competências gerais do documento, não enxergamos possibilidades efetivas, não apenas de reconhecimento como também de sua valorização em um currículo acorrentado a habilidades e competências.

Esse discurso superficial sobre a Diversidade presente no texto da BNCC reflete o pensamento de Neira (2011b), pois o tratamento igualitário, ao invés de se expressar em uma perspectiva crítica diante da Diversidade, posicionase em direção à uniformização dos padrões hegemônicos. As habilidades e competências têm o viés de moldar o indivíduo para atuar na lógica da sociedade neoliberal.

No que se refere à seção da Educação Física, a inserção desse componente na área de Linguagens é justificada pelo fato de as práticas corporais serem "textos culturais passíveis de leitura e produção" (BRASIL, 2017, p.171) por conta dos sentidos e significados que os grupos atribuem a essas manifestações que adotam o conceito de Cultura Corporal de Movimento.

Seguindo essa concepção, os conteúdos estão organizados em seis unidades temáticas: Brincadeiras e Jogos, Danças, Esportes, Ginásticas (demonstração, condicionamento físico e conscientização corporal), Lutas e Práticas Corporais de aventura.

Os conteúdos são distribuídos levando em consideração as competências para cada bloco, mas não são todos trabalhados em todos os blocos, somente Danças, Esportes e Ginásticas. os Jogos e as Brincadeiras não estão presentes no último bloco. As lutas estão ausentes do primeiro e as práticas corporais de aventura estão inseridas apenas nos dois últimos blocos dos anos finais do Ensino Fundamental.

Os conhecimentos das práticas corporais, as competências e as habilidades são articulados com oito dimensões do conhecimento: Experimentação, Uso e apropriação, Fruição, Reflexão sobre a ação, Construção de valores, Análise, Compreensão e Protagonismo comunitário.

O texto da BNCC explica cada uma das dimensões no contexto das práticas corporais e a Educação Física nos anos iniciais e finais do Ensino Fundamental e no Ensino Médio. Como o foco da discussão aqui estabelecida é o Ensino Fundamental, vamos apresentar o que a BNCC estabelece para os anos iniciais e finais Ensino Fundamental desse nível de educação básica.

Entre as onze competências específicas de Educação Física para o Ensino Fundamental, apenas a competência número oito possui relação direta com a Diversidade no currículo quando esta afirma "reconhecer as práticas corporais como elementos constitutivos da identidade cultural dos povos e grupos", (BRASIL, 2017, p. 221).

É nesta perspectiva que Neira (2008) enfatiza que o conjunto de conhecimentos das práticas corporais é definido como um conjunto de fatores de identidade dos sujeitos, pois estas são o que diferenciam os sujeitos e fazem-nos pertencer a determinados grupos.

Por conta desta gama de identidades produzidas a partir das práticas corporais, Neira (2011a) ressalta a importância de contextualizar tais práticas no ambiente escolar. Assim, acreditamos que possa ser construído um currículo na perspectiva da Diversidade cultural, enxergando a contextualização como uma forma de romper com a produção de identidades iguais e, com isso, evitando a universalização de uma determinada cultura sobre as outras.

Nos anos iniciais, a unidade temática Brincadeiras e Jogos traz os elementos da cultura popular e local como foco do primeiro bloco. Nele, verificam-se as brincadeiras e os jogos tradicionais, além das práticas de origem africana e indígena, o que demonstra uma tentativa de reconhecimento da Diversidade cultural nessa unidade temática. O mesmo acontece na unidade de Danças para o primeiro e segundo blocos e na unidade de Lutas para o segundo bloco.

O que nos chama a atenção é que, apesar de esses três conteúdos tratarem de temas relacionados à Diversidade cultural, os conhecimentos de Ginásticas e Esportes, ao que nos parece em uma análise inicial, ainda estão classificados de forma tradicional e aleatória.

O Esporte é trabalhado no primeiro bloco e, 
nas habilidades presentes nesse conteúdo, não é possível enxergar nenhum trato com a Diversidade cultural, o que nos leva a acreditar que a forma como o Esporte é inserido na BNCC mais uma vez reproduzirá os métodos tradicionais do ensino e a lógica social hegemônica. O mesmo é constatado nas Ginásticas, pois a Ginástica geral ganha destaque nos dois blocos dos anos iniciais do Ensino Fundamental.

Quanto ao trato com a diversidade cultural nos conteúdos "Brincadeiras e Jogos", Danças e Lutas apresentados no quadro geral da BNCC (BRASIL, 2017, p. 183), nas habilidades observamos a ênfase na valorização da cultura popular e regional e no reconhecimento e no respeito das diferenças em combate ao preconceito.

No segundo bloco, é dado um destaque especial para as práticas de matrizes africanas e indígenas como forma de valorização cultural. No entanto, cabe ressaltar que o simples reconhecimento e a celebração das diferenças e da Diversidade cultural não garantem a contemplação dos grupos minoritários na escola, tampouco garante a valorização da Diversidade cultural, pois o trato superficial dos objetos de conhecimento da BNCC pode surtir o efeito inverso (NEIRA, 2011a).

Neira (2011a) explicita que um currículo que assegure a Diversidade cultural aborda de forma crítica as diferenças, as identidades e os processos de discriminação. Ou seja, não se trata apenas da boa convivência entre os diversos grupos no ambiente escolar, mas da resistência em combater as opressões e a discriminação em torno das identidades culturais. $\mathrm{O}$ autor problematiza, por exemplo, quais os empecilhos que o currículo enfrenta ao considerar as práticas corporais de matrizes africanas e indígenas, como o Maculelê e as Lutas e Danças indígenas e africanas.

Um dos cuidados no trato com esses conhecimentos é a forma pela qual esses conteúdos podem reforçar o currículo com um caráter globalizante. É importante saber, por exemplo, se o trato com as práticas corporais africanas e indígenas vai realmente ao encontro do reconhecimento da Diversidade ou afirmará o pensamento eurocêntrico de que índios e africanos são todos iguais e celebrar a Diversidade de maneira superficial, sem qualquer criticidade e problematização dos processos discriminatórios que esses povos enfrentaram historicamente.

O texto dá margem para ambas as respostas, pois a sua própria estrutura nos deixa em dúvida sobre esse questionamento, já que as habilidades apresentadas nos conteúdos de "Jogos e Brincadeiras", Danças e Lutas em todos os blocos dos anos iniciais parecem ter sido copiadas umas das outras, sem qualquer cuidado na redação inserida.

Portanto, um documento que não tem esses cuidados em sua redação não nos transmite credibilidade para afirmar com veemência se as propostas de valorização das identidades culturais realmente corroborarão para a construção de um currículo da Educação Física em uma perspectiva cultural.

Nos anos finais do Ensino Fundamental, a Educação Física parece distanciar-se mais ainda da Diversidade Cultural. A unidade temática de "Brincadeiras e Jogos", por exemplo, possuía nos anos iniciais vários elementos de valorização da cultura regional e local e agora se reduz aos jogos eletrônicos em apenas um dos dois blocos. As unidades temáticas Danças, Lutas, Esportes e Ginásticas permanecem com a mesma proposta, descolada da Diversidade cultural. Os dois últimos também apresentam essa característica nas habilidades dos objetos de conhecimento.

Em alguns casos, como nas "Brincadeiras e Jogos" e nas Danças no primeiro bloco, conseguimos identificar alguns elementos que apontam para o trato da Diversidade, mesmo que de forma tímida, ao mencionar que essas práticas devem apontar para a valorização e o respeito aos "sentidos e significados atribuídos a eles por diferentes grupos sociais" (BRASIL, 2017, p.191).

Apesar disso, nas práticas corporais de aventura não conseguimos identificar nas habilidades nenhuma articulação com a valorização e o reconhecimento da Diversidade, sendo essa unidade temática uma novidade prescrita pela BNCC, pois nem os PCN's nem as concepções de Cultura Corporal e Cultura Corporal de Movimento apresentavam essas práticas como um dos conhecimentos da Educação Física, ao menos não de forma isolada, como se encontra nesse documento.

Há avanços nas unidades temáticas de Lutas nos dois blocos e na unidade de Danças no segundo bloco. Nessa última, há duas das quatro habilidades que tratam da Diversidade cultural (BRASIL, 2017, p. 195):

1- "Experimentar e fruir danças de salão, valorizando a diversidade cultural e respeitando a tradição dessas culturas";

2- "Analisar as características (ritmos, 
gestos, coreografias e músicas) das danças de salão, bem como suas transformações históricas e os grupos de origem".

O respeito à tradição das culturas é um importante passo para a sua valorização. Mais do que isso, Kadlubitiski e Junqueira (2009) defendem uma ressignificação da Diversidade, fazendo com que esta rescinda as hierarquias culturais que fundamentam a desigualdade dentro e fora da escola, pois é importante também conhecer as identidades dos diferentes grupos.

Com mais elementos que apontam para a Diversidade, a unidade temática de Lutas tem as seguintes habilidades que seguem nesta direção (BRASIL, 2017, p.193, 197):

1- "Identificar as características (códigos, rituais, elementos técnico-táticos, indumentária, materiais, instalações, instituições) das lutas do Brasil";

2- "Problematizar preconceitos e estereótipos de gênero, sociais e étnicoraciais relacionados ao universo das lutas e demais práticas corporais e estabelecer acordos objetivando a construção de interações referenciadas na solidariedade, na justiça, na equidade e no respeito";

3- "Discutir as transformações históricas, o processo de esportivização e a midiatização de uma ou mais lutas, valorizando e respeitando as culturas de origem".

Neira (2011a) frisa que um currículo sob uma perspectiva cultural, que valorize a Diversidade, precisa criar recursos de resistência às discriminações e às injustiças sociais. Com isso, a problematização de estereótipos e preconceitos é importante para que esses recursos sejam criados e que os membros dos grupos historicamente marginalizados sejam contemplados.

Diante disso, reconhecer as diferenças exige o conhecimento dessas diferenças. É imprescindível, portanto, o conhecimento das culturas de origem dessas práticas corporais, seus processos históricos e os elementos que as constituem como prática.

Em se tratando das Lutas brasileiras, as Lutas de matrizes africanas, afro-brasileiras e indígenas possuem um potencial para esse trato com a Diversidade, especialmente no âmbito cultural. Historicamente, os povos indígenas e africanos sofreram processos de opressão e assimilação da cultura dominante, como se esta fosse a cultura pura ou a verdadeira cultura. Sendo assim, a própria problematização da cultura pode ter um forte apoio no potencial das Lutas brasileiras.

No entanto, ainda nos inquieta a proposta de um currículo baseado em habilidades e competências pela contradição que tais componentes apresentam diante da construção de um currículo que valorize a Diversidade cultural. Vale ressaltarmos que o modelo de "habilidades e competências" foi inserido no processo de mudanças da BNCC (precisamente da segunda para a terceira versão), que se deu com as transformações do contexto político brasileiro no ano de 2017.

Tal fato culminou com mudanças drásticas em todas as áreas, como retirada de direitos, cortes nas políticas de assistência social, redução do salário mínimo e reformas no campo da Educação. Com claros objetivos de favorecer o empresariado, logo o modo de produção capitalista, as medidas do atual governo no âmbito educacional reduzem os objetivos da BNCC aos princípios prescritivos das concepções tradicionais do currículo para formar indivíduos para o mercado.

\section{Considerações finais}

Partindo do que foi exposto, podemos chegar a algumas conclusões como o fato de, desde a década de 1990, algumas políticas públicas educacionais vêm sendo implementadas o reconhecimento da Diversidade no currículo educacional nacional, como os PCN's e a LDB. No entanto, o tema da Diversidade cultural aparece como transversal, quando deveria estar presente em todos os conteúdos trabalhados. Além do mais, um possível avanço para a contemplação da Diversidade cultural que poderia ocorrer com o advento da BNCC não se concretiza no documento, resultado da descontinuidade causada pelos acontecimentos políticos no país.

A BNCC não define qual concepção do objeto da Educação Física a ser utilizado, pois ora utiliza "Cultura Corporal", ora "Cultura Corporal de Movimento". Além disso, não apresenta uma concepção de formação humana nem de sociedade e atende aos interesses neoliberais ao se apropriar de forma superficial de conceitos importantes para o campo acadêmico. A própria Diversidade cultural é tratada com superficialidade. 
Além do mais, a BNCC acaba tornando-se contraditória ao tentar contemplar a Diversidade em um currículo estruturado por habilidades e competências, definindo padrões de formação dos educandos, pois, um currículo a favor da Diversidade cultural deve ser aberto às identidades marginalizadas, o que se torna difícil em um currículo amarrado em habilidades e competências.

Posto isso, a BNCC torna-se apenas um documento com nuances diferenciadas, se comparada aos PCN's, mas não apresenta diferenciais significativos dos Parâmetros elaborados na década de 90 , assim como não rompe com a lógica neoliberal. A BNCC permanece no ecletismo e ainda evidencia o estreitamento da Educação Física e de outras disciplinas em relação à Matemática e à Língua portuguesa, o que demonstra a clara intenção da BNCC em atender às demandas das grandes avaliações realizadas pelo MEC para dar uma resposta aos organismos internacionais.

Em relação aos conteúdos, a BNCC expressa o potencial de apenas alguns conteúdos (Danças, "Jogos e Brincadeiras" e Lutas) na temática da Diversidade cultural, que aparece de forma esporádica em alguns momentos do documento, mas não é contemplada em todos os conteúdos, como observamos nos Esportes e nas Ginásticas, que permanecem com o mesmo caráter tradicional.

Tais conclusões demonstram a necessidade de um debate maior em relação ao currículo da Educação Física e o potencial de seus conteúdos para temáticas importantes na formação dos educandos, pois mais importante do que ensinar conteúdos com seus aspectos técnicos e específicos é a formação humana e, para isso, determinados temas, como a Diversidade Cultural, devem perpassar por todos estes.

\section{Referências}

BETTI, M. Educação Física e sociedade. $1^{\mathrm{a}}$ ed. São Paulo: Movimento, 1991.

BRACHT, Valter. A constituição das teorias pedagógicas da educação física. Cad. CEDES [online], vol. 19, n. 48, 1999. p.69 - 88..

BRASIL. Ministério da educação. Lei de Diretrizes e Bases da Educação Nacional - LDB $n^{\circ}$ 9.394/96, Brasília: Presidência da República, Casa Civil, Sub-
Chefia para Assuntos Jurídicos, 1996.

. Secretaria de Educação Fundamental.

Parâmetros curriculares Nacionais: introdução aos parâmetros curriculares nacionais / Secretaria de Educação Fundamental. Brasília: MEC/SEF, 1997. $126 \mathrm{p}$.

. Secretaria de Educação Fundamental. Parâmetros curriculares nacionais: terceiro e quarto ciclos do Ensino Fundamental: introdução aos parâmetros curriculares nacionais / Secretaria de Educação Fundamental. Brasília: MEC/SEF, 1998. $174 \mathrm{p}$.

Ministério da Educação. Secretaria da Educação Básica. Base Nacional Comum Curricular. Brasília-DF; MEC; CONSED; UNDIME, 2017.

BOSCATTO, J. D., IMPOLCETTO, F. M., DARIDO, S. C. A Base Nacional Comum Curricular: uma proposição necessária para a Educação Física? Motrivivência, v. 28, n. 48, 2016, p. $96-112$.

CHIRINÉA, A. M.; BRANDÃO, C. F. O IDEB como política de regulação do Estado e legitimação da qualidade: em busca de significados. Ensaio: aval. pol. públ. Educ., v. 23, n. 87, abr./jun. 2015, p. 461-484.

COLETIVO DE AUTORES. Metodologia do Ensino da Educação Física. São Paulo: Cortez, 1992.

COLL, Cesar. Psicologia e Currículo: uma aproximação psicopedagógica à elaboração do currículo escolar. $1^{\text {a }}$ ed. São Paulo: Ática, 1996.

DARIDO, S. C. [et al.]. A Educação Física, a formação do cidadão e os Parâmetros Curriculares Nacionais. Revista Paulista de Educação Física, 15, 2001, p. 17-32.

FLEURY, M.T.L. Gerenciando a Diversidade cultural: experiências de empresas brasileiras. $R A E$ Revista de Administração de empresas, São Paulo, v. 40, n. 3, jul./set. 2000, p. 18-25.

GOMES, N. L. Indagações sobre currículo: diversidade e currículo. Organização do documento: Jeanete Beauchamp, Sandra Denise Pagel, Aricélia 
Ribeiro do Nascimento. Brasília: Ministério da Educação, Secretaria de Educação Básica, 2007.

HALL, S. A identidade cultural na pósmodernidade. 12. ed. Rio de Janeiro: Lamparina, 2015.

HANASHIRO, D. M. M.; CARVALHO, S. G. Diversidade cultural: panorama atual e reflexões para a realidade brasileira. $R E A d$, São Paulo, 47. ed, v. 11, n. 5, set./out. 2005.

HENKLEIM, A. P.; SILVA, M. M. A concepção crítico-emancipatória: avanços e possibilidades para a Educação Física escolar. In: XV Congresso Brasileiro de Ciências do Esporte, 2007, Recife. Anais... Recife: CBCE, 2007.

KADLUBITSKI, L.; JUNQUEIRA, S. Diversidade cultural e políticas públicas educacionais. Educação: revista do centro de Educação da UFSM, vol. 34, n. 1, jan./abr., 2009.

KIYINDOU, A. Diversidade cultural. $1^{\text {a }}$ edição. Paris: C \& F Éditions. 2005. Disponível em: <www.vecam.org/article601.html>. Acesso em: 27 jun. 2017.

KUNZ, E. Transformação didático-pedagógica do esporte. $1^{a}$ ed.Ijuí: Unijuí, 1994.

LIMA, M. E; NEIRA, M. G. O currículo da Educação Física como espaço de participação coletiva e reconhecimento da cultura corporal da comunidade. Revista Ibero-americana de Educação, Madrid, v. 51, n. 5, fev. 2010, p.1-10.

LOPES, A. C; MACEDO, E. Teorias De Currículo. $1^{a}$ ed. São Paulo: Cortez, 2011.

MATOS, S. T. Conceitos primeiros de Neoliberalismo. Mediações. v. 13, n. 1-2, jan./jun e jul/dez, 2008, p.192.-.213.

MOREIRA, L. R. [et al.,] Apreciação da base nacional comum curricular e a educação física em foco. Motrivivência, v.28, n.48, 2016, p.61-75.

NEIRA, M. G. Cultura Corporal popular como conteúdo do currículo multicultural da Educação Física. Pensar a prática, Goiânia, v. 11, n. 1, 2008. O currículo cultural da educação física em ação: a perspectiva dos seus autores. 2011a. $332 \mathrm{f}$. Tese (Livre docência) - Metodologia do ensino de Educação Física, Faculdade de Educação, USP, São Paulo, 2011a.

Teorias pós-críticas da educação: subsídios para o debate curricular da Educação Física. Dialogia, São Paulo, n. 14, p. 195-205, 2011 b.

NEIRA, M. G.; NUNES, M. F. R. Contribuições dos estudos culturais para o currículo da educação física. Revista Brasileira de Ciências do Esporte. Florianópolis, v.33, n.3, p.671-685, jul/set. 2011.

NEIRA, M. G.; SOUZA JUNIOR, M. A Educação Física na BNCC: procedimentos, concepções e efeitos. Motrivivência, v. 28, n. 48, 2016, p. 188206.

NUNES, M. L. F.; RÚBIO, K. O(s) currículo(s) da Educação Física e a identidade dos seus sujeitos. Currículo sem fronteiras, Mangualde, Portugal, v. 8, n. 2, jul./dez. 2008, p. 55-77.

PINHEIRO, G. C. G. Teoria curricular crítica e póscrítica: uma perspectiva para a formação inicial de professores para a educação básica, ANALECTA, Guarapuava-PR, v. 10, n. 2, jul/dez, 2009, p 11.-.25.

RIBEIRO, M. P. Teorias críticas e pós-críticas: pelo encontro em detrimento do radicalismo, Movimento, Rio de Janeiro, ano 3, n. 5, 2016, p. 284..-.317.

RODRIGUES, A. T. Gênese e sentidos dos parâmetros curriculares nacionais e seus desdobramentos para a Educação Física escolar brasileira. 2001. 156 f. Dissertação (Mestrado em Educação). Faculdade de Educação, Universidade Federal de Goiás, Goiânia, 2001. Recensão de: SOUZA, L. C. Revista Pensar a Prática, v. 9, n. 2, 2006.

Base Nacional Comum Curricular para a área de linguagens e o componente curricular Educação Física, Motrivivência, v. 28, n. 48, 2016, p.32.-.41.

SACRISTÁN, J. G. A Educação que temos, a Educação que queremos. In: IMBERNÓN, F. (org.). A educação no século XXI: os desafios do futuro imediato. Trad. Ernani Rosa. 2. ed. Porto Alegre: Artes Médicas Sul, 2000, p. 37-61. 
SILVA, M. J. A.; BRANDIM, M. R. L.

Multiculturalismo e Educação: em defesa da Diversidade cultural. Diversa, ano 1, n. 1, jan/jun. 2008, p. 51-56.

SILVA, T. T. Documentos de identidade: uma introdução às teorias do currículo. 3. ed. Belo Horizonte: Autêntica, 2010.

SOARES, C. L. Educação Física: raízes europeias e Brasil. $1^{a}$ ed. Campinas: Autores Associados, 1994.

\section{Sobre os autores}

Marcio Antonio Raiol dos Santos: Licenciado em Educação Física e Doutor em Educação. Professor Titular da Universidade Federal do Pará, lotado no Núcleo Transdisciplinar de Estudos da Educação Básica - NEB, docente permanente do Programa de Pós-Graduação em Currículo e Gestão da Escola Base - PPEB/UFPA, Líder do Grupo de Pesquisa em Práticas Pedagógicas para a Educação Básica - GPRAPE.

Pedro Paulo Souza Brandão: Licenciado em Educação Física e Mestre em Currículo e Gestão da Escola Básica, Professor efetivo da Rede Municipal de Educação de Belém-PA, membro do Grupo de Pesquisa em Práticas Pedagógicas para a Educação Básica-GPRAPE e, do Grupo de Pesquisa Ressignificar- Experiências inovadoras na formação de professores.

Recebido em dezembro de 2017.

Aprovado em março de 2018. 